\title{
Adenoid cystic carcinoma, dynamic Eustachian tube imaging and a touch of magic
}

As the year draws to an end, it gives me time to reflect on what a momentous year it has been for The Journal of Laryngology \& Otology. Earlier this year, The Journal supported the publication of the fifth edition of the UK Head and Neck Cancer Guidelines, a truly collaborative, multidisciplinary project which guides clinicians on best practice in head and neck cancer, endorsed by leading national specialty associations involved in head and neck cancer care. ${ }^{1}$

Another collaborative effort on an international scale comes in this month's issue, with the publication of an article written by members and invitees of the International Head and Neck Scientific Group. ${ }^{2}$ The group have studied and reported on the behaviour of adenoid cystic tumours arising in rare sites outside of the salivary glands, including the sinonasal tract, nasopharynx, lacrimal gland and external auditory canal. Of the 774 patients identified worldwide, only 5.3 per cent developed documented regional lymph node metastases. The authors conclude that elective neck dissection is not routinely indicated in most patients with these tumours. In addition, the behaviour of adenoid cystic carcinoma at these sites was shown to parallel its behaviour in major salivary glands. ${ }^{3,4}$

Imaging of the Eustachian tube in real time has proven difficult up until now, both because of its anatomical orientation, and the dynamic nature of its open and closed states. A state-of-the-art technique reported by Jufas et al. in this month's issue overcomes some of the challenges associated with conventional computed tomography (CT) imaging of the Eustachian tube by applying a novel imaging modality known as four-dimensional (4D) $\mathrm{CT}^{5}{ }^{5}$ This imaging technique provides a fourth dimension to $\mathrm{CT}$ sequences of the Eustachian tube (namely time), enabling dynamic imaging. Accompanying the article is a featured video demonstrating a 4D CT cine sequence of the Eustachian tube during a Valsalva manoeuvre (downloadable from: https://goo.gl/AzeLtO). This innovative technique may assist in the diagnosis of patients with abnormal Eustachian tube states, such as Eustachian tube dysfunction or patulous Eustachian tube. Another advantage includes its ability to monitor responses to newer treatments. ${ }^{6-8}$

An elegant study by Mahajan et al. in this month's issue measured various cardiopulmonary physiological parameters in 25 children with adenotonsillar hypertrophy, both pre- and post-operatively. ${ }^{9}$ The authors found that adenotonsillar hypertrophy affects cardiopulmonary function, which eventually becomes irreversible with time. Furthermore, the authors found significant improvements in pulmonary flow acceleration time, mean pulmonary arterial pressure and tricuspid regurgitation following adenotonsillectomy. The article argues in favour of early intervention in children with obstructive sleep apnoea secondary to adenotonsillar hypertrophy, in order to avoid the development of irreversible cardiopulmonary complications.

Also featuring in this month's issue, Stavrakas et al. continue the regenerative medicine theme and explore the role of platelet-rich plasma in otolaryngology, ${ }^{10,11}$ and Mudry et al. unleash some of the magic behind Blakesley and his ethmoid forceps one hundred years on. ${ }^{12}$

We would like to take this opportunity to thank all those who have contributed to the success of this year's journal, including all the authors, Editors, Assistant Editors, production staff, our publishing partners at Cambridge University Press and all other colleagues at The Journal for their hard work during 2016. Finally, we wish all of our readers a happy and successful 2017.

\section{JONATHAN FISHMAN ROBIN YOUNGS EDWARD FISHER MUSHEER HUSSAIN Senior Editors}

\section{References}

1 Paleri V, Roland N. Introduction to the United Kingdom National Multidisciplinary Guidelines for Head and Neck Cancer. J Laryngol Otol 2016;130(suppl S2):S3-4

2 International Head and Neck Scientific Group. Cervical lymph node metastasis in adenoid cystic carcinoma of the sinonasal tract, nasopharynx, lacrimal glands, and external auditory canal: a collective international review. J Laryngol Otol 2016; 130:1093-7

3 Ali S, Yeo JC, Magos T, Dickson M, Junor E. Clinical outcomes of adenoid cystic carcinoma of the head and neck: a single institution 20-year experience. J Laryngol Otol 2016;130:680-5

4 Sood S, McGurk M, Vaz F. Management of salivary gland tumours: United Kingdom National Multidisciplinary Guidelines. J Laryngol Otol 2016;130(suppl S2):S142-9

5 Jufas N, Deveau N, Bance M. Dynamic cine imaging of the Eustachian tube using four-dimensional computed tomography. J Laryngol Otol 2016;130:1158-60

6 Jufas N, Patel N. Transtympanic balloon dilatation of the eustachian tube: systematic review. J Laryngol Otol 2016;130: 425-30 
7 Mackeith SA, Bottrill ID. Polydimethylsiloxane elastomer injection in the management of the patulous eustachian tube. $J$ Laryngol Otol 2016;130:805-10

8 Rodrigues JC, Waddell A, Cook JL. A novel, computed tomography guided, trans-cutaneous approach to treat refractory autophony in a patient with a patulous eustachian tube. J Laryngol Otol 2014;128:182-4

9 Mahajan M, Thakur JS, Azad RK, Mohindroo NK, Negi PC. Cardiopulmonary functions and adenotonsillectomy: surgical indications need revision. J Laryngol Otol 2016;130:1120-4
10 Stavrakas M, Karkos PD, Markou K, Grigoriadis N. Platelet rich plasma in otolaryngology. J Laryngol Otol 2016;130: 1098-102

11 Wormald JC, Fishman JM, Juniat S, Tolley N, Birchall MA. Regenerative medicine in otorhinolaryngology. J Laryngol Otol 2015;129:732-9

12 Mudry A, Lubbers W, Pirsig W. One hundred years ago: the physician magician Blakesley presented his ethmoid forceps. J Laryngol Otol 2016;130:1086-92 